\title{
PERANCANGAN SISTEM INFORMASI KREDIT MOTOR TOSSA DENGAN MENGGUNAKAN BORLAND DELPHI 7.0 PADA PT. TOSSA SALIMAS FINANCE
}

\author{
Agus Sukoco \\ Program Studi Teknik Informatika \\ Fakultas Ilmu Komputer \\ Universitas Bandar Lampung \\ Jln. Z.A. Pagar Alam No.26 Labuhan Ratu Bandar Lampung 35142 \\ Telp. (0721) 701463, (0721) 701979 Fax. (0721) 701467 Web. www.ubl.ac.id
}

\begin{abstract}
Abstrak
PT.Tossa Salimas Finance adalah perusahaan yang bergerak dibidang pembiayaan kredit sepeda motor merk TOSSA yang berpusat di semarang dan mempunyai cabang di 28 propinsi di indonesia. Salah satu cabang PT. Tossa Salimas Finance berada dibandar lampung yang berkantor dipahoman bandar lampung. Semenjak berdiri pada Oktober 2003 PT. Tossa Salimas Finance Bandar Lampung belum menggunakan media komputerisasi. Komputer digunakan hanya untuk melakukan penyimpanan data manual dengan microsoft excel dan menggunakan microsoft word sebagai pengolah kata. Pada tahun 2007, konsumen PT. Tossa Salimas Finance Bandar Lampung sudah lebih dari 3.000 konsumen sehingga perusahaan berinisiatif untuk mengolah data dengan komputer sederhana. Sehingga banyak terjadi kesalahan seperti pembayaran tidak berkala, lamanya proses, dan borosnya biaya dalam mengelola setiap transaksi karena banyak kertas dibutuhkan dalam setiap transaksi sering terjadi. Hal ini ditambah kurangnya pengawasan dari pimpinan sehingga banyak motor yang mengalami kendala saat pengambilan BPKB (Bukti Kepemilikan kendaraan Bermotor ).

Berdasarkan penjelasan diatas maka penulis Merancang sistem informasi penanganan kredit motor yang baik agar dapat mengurangi biaya yang besar dan waktu yang relatif lama menjadi biaya yang ringan dan waktu yang efisen dengan data jauh lebih akurat dan Mengurangi prosedur kerja yang yang kurang efektif. Prosedur tersebut meliputi pencarian data konsumen dan membuatkan pos pelayanan pembayaran sehingga jarak tempuh yang jauh akan dapat ditempuh dengan jarak pendek.
\end{abstract}

Kata Kunci : Borland Delphi, Perancangan, Kredit, Sistem Informasi

\section{PENDAHULUAN}

Kamajuan teknologi tentu kurang maksimal diterapkan kepada generasi berikutnya jika tidak ditunjang dengan pendidikan. Universitas Bandar Lampung sebagai institusi formal yang mendidik generasi bangsa dimasa sekarang dan masa yang akan datang. Agar siap terjun didunia kerja Universitas Bandar Lampung berusaha menyelaraskan program pendidikan dengan metode pekerjaan dilapangan.
PT.Tossa Salimas Finance adalah perusahaan yang bergerak dibidang pembiayaan kredit sepeda motor merk TOSSA yang berpusat di semarang dan mempunyai cabang di 28 propinsi di indonesia. Salah satu cabang PT. Tossa Salimas Finance berada dibandar lampung yang berkantor dipahoman bandar lampung. Semenjak berdiri pada Oktober 2003 PT. Tossa Salimas Finance Bandar Lampung belum menggunakan media komputerisasi. Komputer digunakan hanya untuk melakukan penyimpanan data manual dengan microsoft excel dan menggunakan microsoft word 
sebagai pengolah kata. Pada tahun 2007, konsumen PT.

Tossa Salimas Finance Bandar Lampung sudah lebih dari 3.000 konsumen sehingga perusahaan berinisiatif untuk mengolah data dengan komputer sederhana. Tetapi hal tersebut gagal karena aplikasi yang digunakan menggunakan dbase+ yang belum sempurna ditambah lagi banyak karyawan yang tidak mengerti program tersebut sehingga dalam waktu 3 bulan perusahaan kembali menggunakan pengolahan data manual. Sehingga banyak terjadi kesalahan seperti pembayaran tidak berkala, lamanya proses, dan borosnya biaya dalam mengelola setiap transaksi karena banyak kertas dibutuhkan dalam setiap transaksi sering terjadi. Hal ini ditambah kurangnya pengawasan dari pimpinan sehingga banyak motor yang mengalami kendala saat pengambilan BPKB ( Bukti Kepemilikan kendaraan Bermotor ). Berdasarkan pengamatan penulis pada PT. Tossa Salimas Finance Bandar Lampung perusahaan mendukung kegiatan penulis mengingat pentingnya manfaat yang diperoleh saat operasional pekerjaan berjalan, sehingga data akan lebih efektif dan efisien.

\subsection{Permasalahan}

Dari latar belakang yang telah ditemukan diatas, maka penulis merumuskan masalah sebagai berikut:

1. Penanganan konsumen pada PT. Tossa Salimas Finance masih melakukan cara manual sehingga waktu menjadi tidak efektif, biaya yang boros dan data yang kurang akurat.

2. Lemahnya sumber daya manusia yang terlibat langsung dalam penganganan kredit sehingga sering terjadi manipulasi data-data konsumen yang menyebabkan kerugian perusahaan ataupun konsumen.

3. Pengawasan pimpinan yang lemah menjadi salah satu penyebab lambannya kinerja 5

\subsection{Batasan Masalah}

Pada karya ilmiah ini penulis membuat batasan masalah pada sistem penanganan konsumen mulai dari pengajuan syarat kredit konsumen sampai pada terbitnya BPKB sebagai bukti sah motor milik konsumen yang diberikan kepada konsumen.

\subsection{Tujuan Penulisan}

Tujuan penulis melakukan penulisan ini adalah

1. Merancang sistem informasi penanganan kredit motor yang baik agar dapat mengurangi biaya yang besar dan waktu yang relatif lama menjadi biaya yang ringan dan waktu yang efisen dengan data jauh lebih akurat.

2. Mengurangi prosedur kerja yang yang kurang efektif. Prosedur tersebut meliputi pencarian data konsumen dan membuatkan pos pelayanan pembayaran sehingga jarak tempuh yang jauh akan dapat ditempuh dengan jarak pendek.

3. Meningkatkan sumber daya manusia khususnya yang terlibat langsung dalam penganganan kredit.

4. Agar keilmuan penulis lebih memiliki daya guna dan dapat diterapkan didunia kerja seperti PT. Tossa Salimas Finance tempat penelitian penulis.

\subsection{Pengertian Perancangan}

Perancangan adalah proses, cara, perbuatan merancang. ( Tim Penyusun Kamus Besar Bahasa Indonesia Depdikbud, 2005;308)

\subsection{Pengertian Sistem Informasi}

Sistem informasi adalah suatu sistem dalam suatu organisasi yang mempertemukan kebutuhan pengolahan transaksi harian, mendukung operasi, bersifat manajerial, dan kegiatan strategi dari suatu organisasi dan menyediakan pihak luar tertentu dengan laporan-laporan yang diperlukan (Robert A.Letch/K. Roscoe Davis, 1983:46).

Arti lain sistem informasi adalah sekumpulan hardware dan software, brainware, prosedure dan aturan yang diorganisasikan secara integral untuk mengolah data menjadi informasi yang lebih berguna sehingga dapat memecahkan masalah dalam pengambilan keputusan (http://id.wikipedia.org/wiki/sistem_informasi).

\subsection{Komponen Sistem Informasi}

Komponen sistem informasi terdiri dari :

\section{Blok Masukan (Input block)}


Input mewakili data yang masuk kedalam sistem informasi. Input termasuk metodemetode dan media untuk menangkap data yang akan dimasukan, yang dapat berupa dokumen-dokumen dasar.

\section{Blok Model}

Blok ini terdiri atas kombinasi prosedur, logika dan model matematik yang akan memanipulasi data input dan data yang akan tersimpan dibasis data dengan cara yang sudah tentu menghasilkan keluaran yang diinginkan.

3. Blok Keluaran

Blok keluaran ini adalah keluaran yang merupakan informasi yang berkualitas dan dokumentasi yang berguna untuk semua tingkatan manajemen dan semua pemakai sistem.

\section{Blok Teknologi}

Teknologi merupakan "kotak alat", dalam system informasi. Teknologi yang digunakan untuk menerima input, menjalankan model, menyimpan dan mengakses data, menghasilkan dan mengirim keluaran serta membantu mengendalikan sistem secara keseluruhan.

\section{Blok Basis Data}

Basis data atau database merupakan kumpulan data yang saling berhubungan dengan yang lainnya, tersimpan pada perangkat keras komputer dan digunakan perangkat lunak dalam memanipulasinya. Basis data diakses dengan menggunakan perangkat lunak yang disebut DBMS ( Database Management System ).

\section{Blok Kendali}

Sistem informasi dapat rusak atas kejadian -kejadian seperti bencana alam, kerugian-kerugian, kegagalan sistem itu sendiri, sabotase dan lainya. Perlu dirancang beberapa pengendali agar halhal tersebut dapat dicegah.(Raymond Mcleod: edisi 7 :71)

Perancangan sistem informasi menurut penulis adalah merancang atau membuat suatu proses dengan menggunakan sekumpulan hardware dan software, brainware, prosedure dan aturan yang diorganisasikan secara integral untuk mengolah data menjadi informasi yang lebih berguna secara efektif, efisien dan tepat guna sehingga dapat memecahkan masalah dalam pengambilan keputusan.

\subsection{Borland Delphi 7.0}

Delphi adalah sebuah bahasa pemrograman dan lingkungan pengembangan perangkat lunak. Produk ini dikembangkan oleh Borland (sebelumnya dikenal sebagai Inprise). Bahasa Delphi, yang sebelumnya dikenal sebagai object pascal (pascal dengan ekstensi pemrograman berorientasi objek (PBO/OOP)) pada mulanya ditujukan hanya untuk Microsoft Windows, namun saat ini telah mampu digunakan untuk mengembangkan aplikasi untuk Linux dan Microsoft .NET framework (lihat di bawah). Dengan menggunakan Free Pascal yang merupakan proyek opensource, bahasa ini dapat pula digunakan untuk membuat program yang berjalan di sistem operasi Mac OS X dan Windows CE

Umumnya delphi lebih banyak digunakan untuk pengembangan aplikasi desktop dan enterprise berbasis database, tapi sebagai perangkat pengembangan yang bersifat general-purpose ia juga mampu dan digunakan dalam berbagai jenis proyek pengembangan software. Ia juga yang dikenal sebagai salah satu yang membawa istilah $R A D$ tool, kepanjangan dari Rapid Application Development, saat dirilis tahun 1995 untuk windows 16-bit. Delphi 2, dirilis setahun kemudian, mendukung lingkungan windows 32-bit, dan versi $\mathrm{c}++, \mathrm{C}++\mathrm{Builder}$, dirilis beberapa tahun kemudian. Pada tahun 2001 sebuah versi linux yang dikenal sebagai Kylix tersedia. Dengan satu rilis baru setiap tahunnya, pada tahun 2002 dukungan untuk Linux (melalui Kylix dan CLX component library) ditambahkan dan tahun 2003 .NET mulai didukung dengan munculnya Delphi.Net (Delphi 8)

Chief Architect yang membidani Delphi, dan pendahulunya Turbo Pascal, adalah Anders Hejlsberg sampai kemudian ia pindah ke Microsoft tahun 1996 di mana ia sebagai chief designer C\# dan termasuk orang kunci dalam perancangan Microsoft .Net Framework. Dukungan penuh untuk .Net ditambahkan pada Delphi 8 (dirilis pada bulan Desember 2003 ) dengan penampilan user interface (look and feel) mirip dengan Microsoft Visual Studio .NET 
(http://id.wikipedia.org/wiki/bahasapemrograman) Delphi 2005 (nama lain dari Delphi 9) mendukung code generation baik untuk win32 maupun .NET, dan seperti yang telah dikenal, fitur-fitur manipulasi data secara live dari database secara design-time. Ia juga membawa banyak pembaruan pada IDE secara signifikan.

Para penganjur delphi mengklaim dengan bahasa pemrograman Delphi, IDE dan component library (VCL/CLX) yang disediakan oleh vendor tunggal memungkinkan satu paket yang lebih konsisten dan mudah dikenali. Produk delphi ini didistribusikan dalam beberapa rancangan: Personal, Professional, Enterprise (sebelumnya Client/Server) dan Architect.

\subsubsection{Kelebihan Menggunakan delphi}

Delphi membawa keuntungan-keuntungan /

kelebihan sebagai berikut:

- Komunitas pengguna yang besar pada Usenet maupun web.

- Dapat mengkompilasi menjadi single executable, memudahkan distribusi dan meminimalisir masalah yang terkait dengan versioning

- Banyaknya dukungan dari pihak ketiga terhadap VCL (biasanya tersedia berikut source codenya) ataupun tools pendukung lainnya (dokumentasi, tool debugging)

- Optimasi kompiler yang cukup cepat

- Mendukung multiple platform dari source code yang sama

Selain itu juga dalam pemrograman delphi mempunyai karakteristik pendukung yaitu :

1. Tidak case sensitive

Pemrograman delphi tidak case sensitive, artinya delphi tidak membedakan huruf besar dan huruf kecil.

2. Object based.

Delphi merupakan pemgraman berorientasi object, artinya hampir seluruhnya merupakan object. Seperti button yang merupakan komponen turunan dari object dengan nama TObject. Object ini merupakan object utama dalam delphi. Hampir semua komponen diturunkan dari object ini. Dari turunan object pun kita bisa menurunkan object lain, misalkan kita membuat komponen yang diturunkan langsung dari button, maka komponen buatan kita memiliki properti yang sama dengan object diatasnya yaitu button.

\section{Pemrograman delphi merupakan} pengembangan dari pemrograman bahasa pascal.

Sehingga bahasanya hampir mirip, tatapi memiliki kelebihan yang sangat banyak, seperti tipe data yang lebih fleksibel dan besar.

\section{Modularitas}

Setiap aplikasi yang kita buat dengan delphi akan memiliki banyak sekali file modul yang terpisah. Bisa kita lihat pada clausa uses pada setiap unit, misalkan dalam contoh kita kali ini, kita menggunakan modul form, window, dll. Tetapi dalam pengembangan yang lebih lanjut kita bisa membuat modul khusus untuk aplikasi kita, misalnya modul .dll

Standarisasi penulisan varibale.

Sebenarnya tidak ada aturan yang jelas, tetapi penggunaan standarisai ini hanyalah untuk memudahkan ketika kita bekerja dalam team work

1. Selalu menggunakan kata yang singkat dan mencerminkan tipe datanya, misalkan variable str untuk tipe data string.

2. Gunakan bahasa inggris.

3. Jika variable bersifat global untuk unit tersebut saja maka pendeklarsikan dalam statement privat.

4. Jika variable bersifat global untuk semua unit maka pendeklarsikan dalam statement public.

\subsubsection{Kelemahan Menggunakan Delphi}

Berikut ini kerugian / kelemahannya:

- Partial single vendor lock-in (Borland dapat menetapkan standar bahasa, kompatibilitas yang harus mengikutinya)

- Terbatasnya kamampuan portabilitas antar-platform OS (sebelum ada kylix)

- Akses pada platform dan library pihak ketiga membutuhkan file-file header yang diterjemahkan ke dalam bahasa pascal

- Dokumentasi atas platform dan tehniktehnik yang menyertainya sulit ditemukan dalam bahasa pascal (contoh akses COM dan Win32) 


\subsection{Perancangan Input}

1. Menu Utama

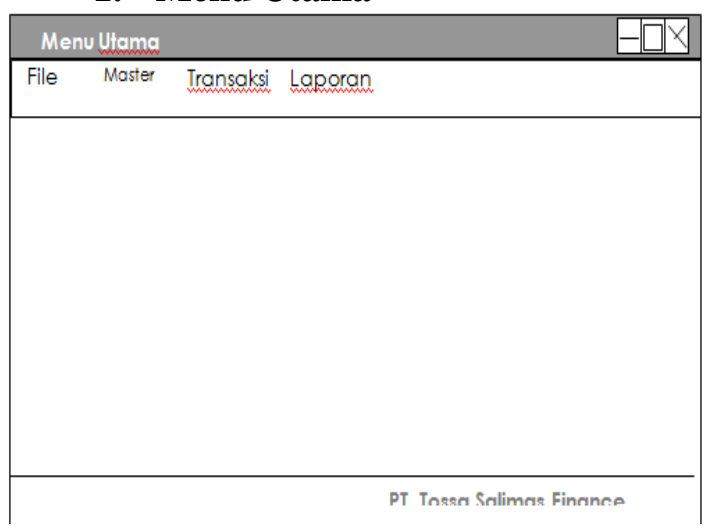

Gambar 3.1 Menu Utama

\section{Form Konsumen}

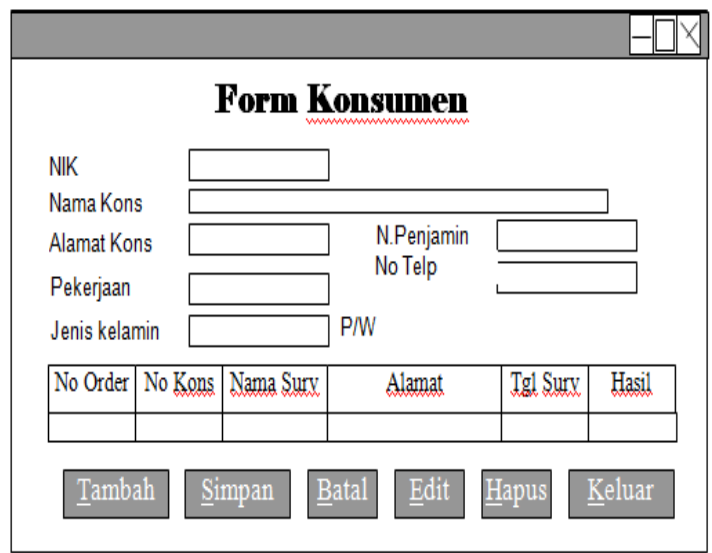

Gambar 3.2 Form Konsumen

\section{Form Surveyer}

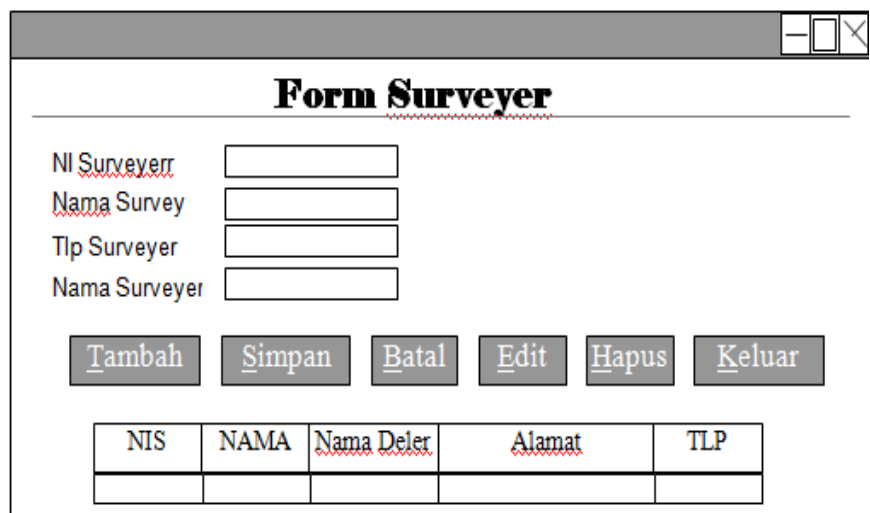

Gambar 3.3 Form Suveyer

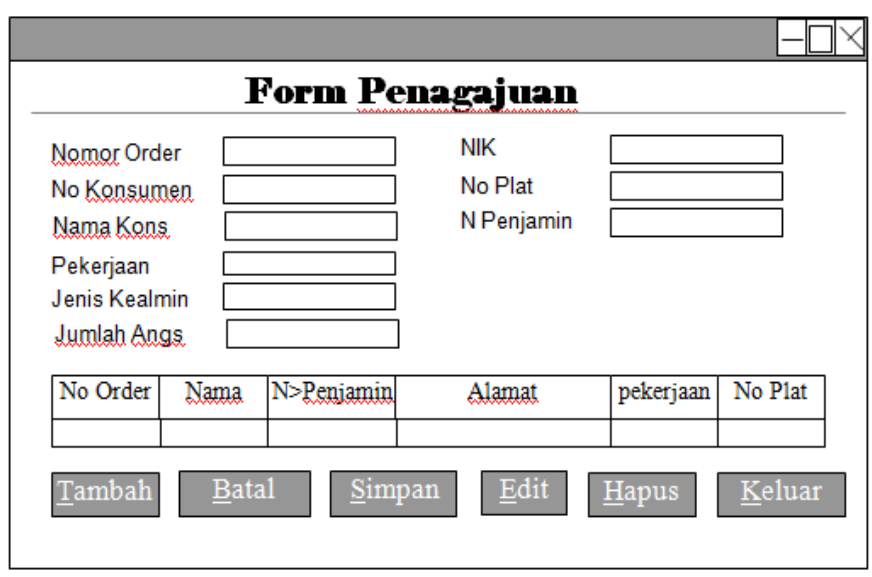

Gambar 3.4 Form Pengajuan

\section{Form Kelayakan}

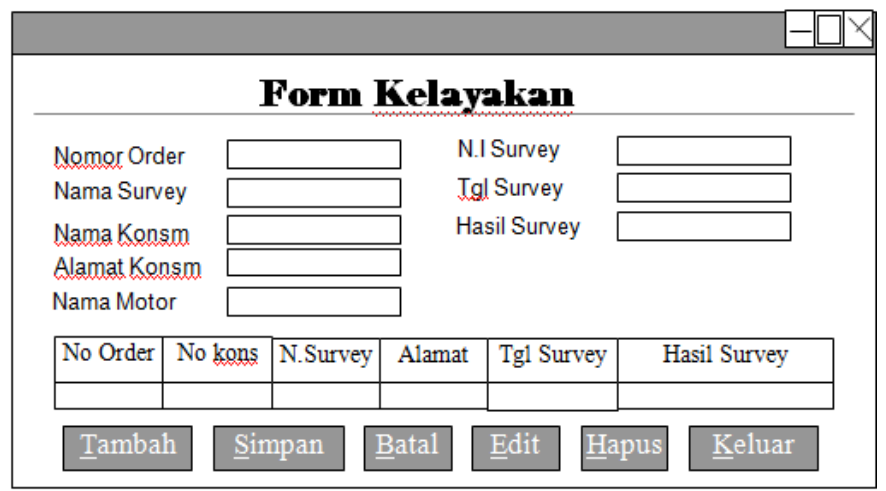

Gambar 3.5 Form Kelayakan

\section{Form Pengiriman}

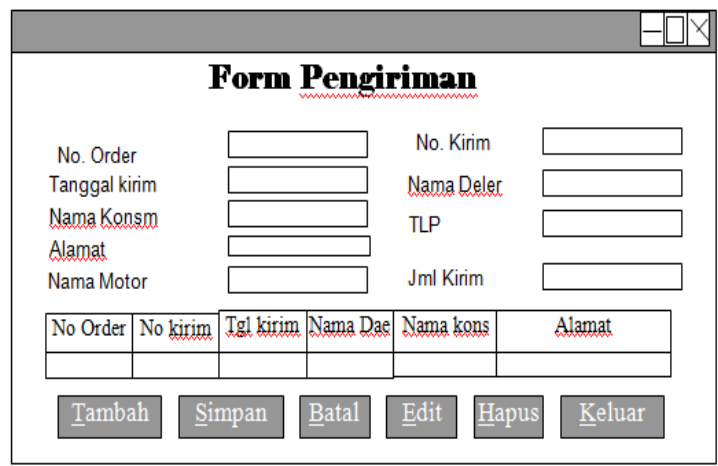

Gambar 3.6 Form Pengiriman

\section{Form Pengajuan}

\section{Form Pengajuan}




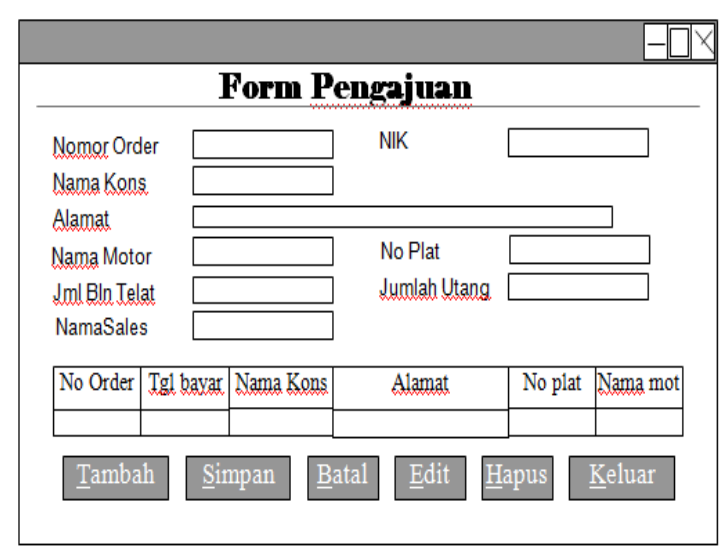

Gambar 3.7 Form Pengajuan

\section{Form Angsuran}

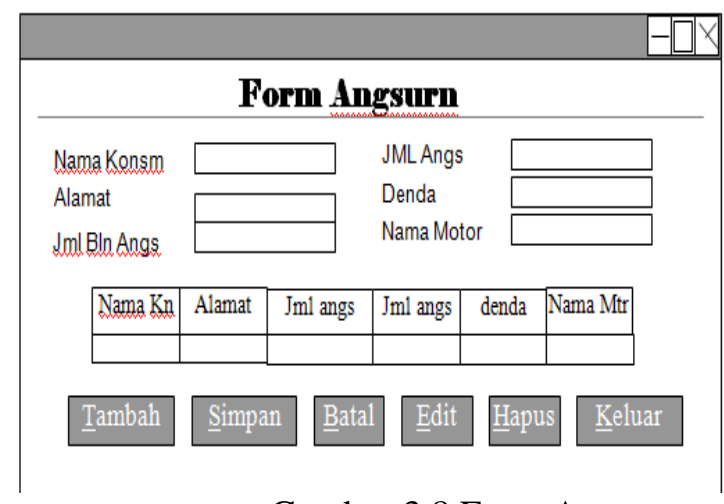

Gambar 3.8 Form Angsuran

\section{Form Data Masalah}

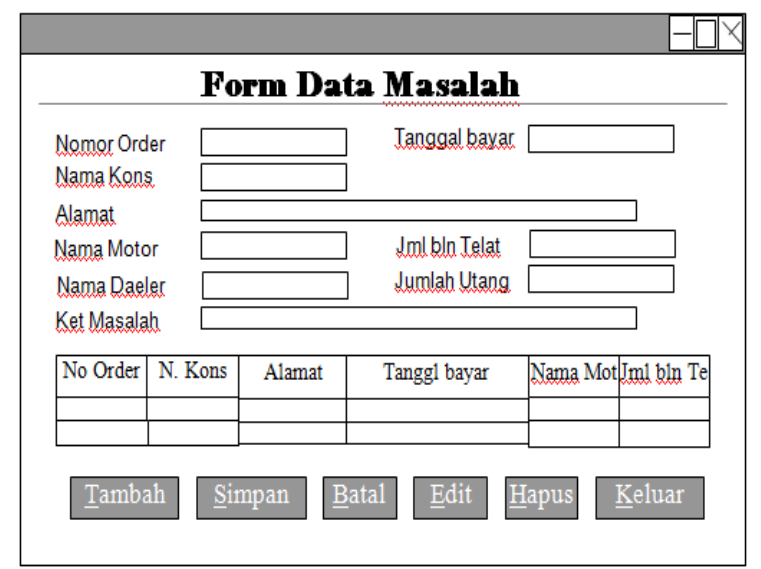

Gambar 3.9 Form Data Masalah

\section{Form Pelunasan}

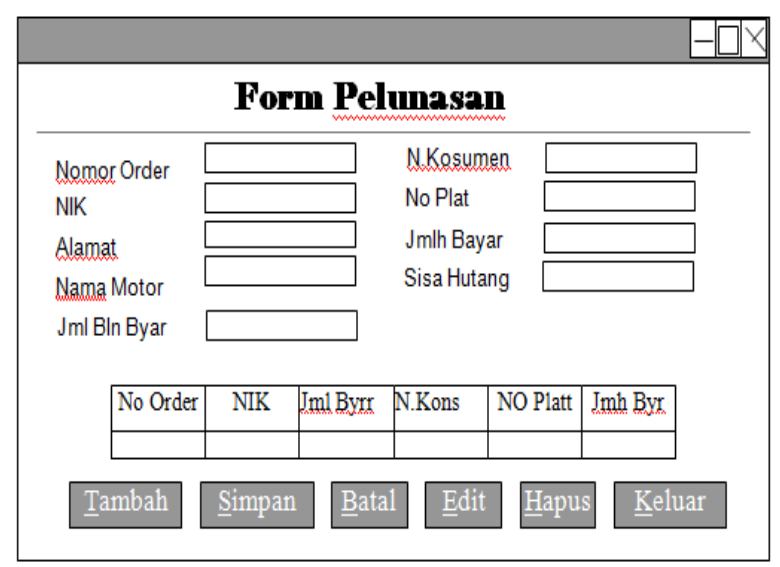

Gambar 3.10 Form Pelunasan

\subsection{Implementasi Program}

Untuk mengimplementasi sistem informasi pemberian kredit motor tossa pada PT. Tossa Salimas Finance agar berjalan dengan baik diperlukan beberapa unsur terkait agar sistem yang dibangun berjalan secara maksimal dan tidak banyak mengalami kendala

Beberapa unsur yang diperlukan untuk menunjang maksimalnya kerja sistem informasi pemberian kredit motor tossa pada PT. Tossa Salimas Finance adalah :

1. Sumber daya manusia ( brainware ) Sumber daya manusia menjadi faktor penting dalam menunjang sistem informasi. Manusia sebagai kontrol awal terhadap input oputput sistem, jika pemberian input yang salah secara otomatis output yang diterima juga akan salah. Oleh karena itu, untuk meningkatkan sumber daya manusia yang berkualitas diperlukan waktu dan biaya yang tidak sedikit. Biasanya untuk meningkatkan sumber daya manusia yaitu dengan mengadakan pelatihan dan terus memberikan support kerja agar karyawan lebih termotivasi dan bekerja dengan baik. Sumber daya manusia yang dimaksud dalam sistem yaitu karyawan yang masuk dalam bagian-bagian pemberian kredit sampai pada pemberian BPKB sebagai proses akhir kerja sistem.

2. Alat (Software dan hardware) 
Perangkat lunak dan perangkat keras diperlukan dalam menunjang kerja sistem. Kedua perangkat ini sebagai pemroses selanjutnya setelah lolos dari proses manual yang dilakukan manusia oleh karena itu diharapkan agar pemakaian perangkat disesuaikan dengan kebutuhan sehingga perangkat akan lebih membantu pekerjaan, tidak membuat tambah banyak dan rumit pekerjaan yang dilakukan operator. Alat yang baik paling tidak memenuhi standarisasi pengerjaan seperti usulan tertampil pada bab 3 .

3. Area Kerja

Dalam mengimplementasi sistem informasi kita juga wajib memperhatikan daerah kerja sistem informasi. Daerah yang dimaksud yaitu penempatan perangkat pendukung dan operator, jika diperlukan alat tambahan lain untuk mempercepat arus dan sebagainya sebaiknya ditambah dengan perangkat yang baik sehingga dalam pelaksanaannya unsur tersebut dapat kerja secara maksimal.

\subsection{Pemeliharaan Program}

Dalam pemeliharaan sebaiknya diperlukan administrator sistem yang mengatur dan memelihara sistem agar sistem dapat berjalan baik dan masing masing bagian dapat bekerja dengan fungsinya tidak bercabang. Pemeliharaan program diperlukan waktu berkala dan tidak berkala. Pemeliharaan dengan waktu berkala yaitu sebaiknya program diperbaharui dan lebih ditingkatkan lagi setiap 6 bulan sekali sehingga berbagai kekurangan yang ada dapat diperbaiki. Sedangkan pemeliharaan program tidak berkala merupakan kontrol setiap saat yang dilakukan seorang administrator.

\subsection{Simpulan dan Saran}

\subsubsection{Kesimpulan}

Dari uraian yang telah dibahas pada bab-bab terdahulu, maka penulis menyimpulkan bahwa pelayanan kredit motor tossa pada PT. Tossa Salimas Finance masih menggunakan system manual. Pelayanan manual tersebut meliputi pemberian informasi kredit, pengajuan kredit, pembiayaan, informasi penagihan dan penarikan dan pendataan konsumen bermasalah.
Banyaknya system manual yang dilakukan dalam pelayanan sering mengakibatkan bermacam kendala seperti lambatnya pelayanan, panjangnya antrian dan seringnya terjadi kesalahan data, baik rangkap atau manipulasi data. Apalagi pada bagian pemberian kredit kadang bekerja pada kontrol yang lemah sehingga kemungkinan terjadinya kesalahan sering terjadi.

Untuk mengatasi berbagai macam kendala tersebut penulis memberikan salah satu solusi pemecahan masalah dengan membuatkan sistem komputerisasi yang nantinya diharapkan akan banyak mengurangi kesalahan, mempercepat pelayanan dan mengurangi biaya dalam jangka waktu yang panjang.

\subsubsection{Saran}

Adapun saran yang dapat penulis berikan untuk PT. Tossa Salimas Finance ( PT. TSF ) adalah sebagai berikut :

1. Agar pimpinan PT. Tossa Salimas Finance lebih meningkatkan control pengawasan, sehingga koordinasi tetap terjalin dan kesalahan dapat diminimalisir.

2. Agar PT. Tossa Salimas Finance dapat menggunakan Sistem komputerisasi dalam memberikan pelayanan dan pemberian kredit pada konsumen sehingga waktu proses didapatkan akan lebih cepat, tepat sasaran dan informasi sangat akurat.

\section{DAFTAR PUSTAKA}

Abdul Kadir Konsep dan Tuntunan Praktis Basis data, Penerbit Andi Yogyakarta, Yogyakarta :1998

H.M. Jogiyanto. Analisis dan Desain Sistem informasi, Penerbit Andi Yogyakarta, Yogyakarta :1992

Leman, S.Kom. Sistem Informasi Terkini, Penerbit Andi Offset, Yogyakarta, 1998.

Raymond McLeod, Jr. Sistem Informasi Manajemen.Jilid 1. Edisi Ketujuh. Penerbit PT.Prenhakkindo Jakarta :1997

EM. Zulfajri dan Ratu Aprillia Senja. Kamus Bisnis dan Manajemen.Penerbit Renika Cipta. Jakarta : Edisi Revisi. 